\title{
Getting started with your veterinary nursing dissertation: what can I research?
}

\author{
by Mansbridge, S.C. and Buckley, L.A.
}

Copyright, publisher and additional information: This is the authors' accepted manuscript. The final published version (version of record) is available online via Taylor \& Francis.

Please refer to any applicable terms of use of the publisher.

DOI: https://doi.org/10.1080/17415349.2018.1459336 Harper Adams University 


\title{
Getting started with your veterinary nursing dissertation: what can I research?
}

Stephen C. Mansbridge BSc (Hons), PhD, CBiol, MRSB, FHEA, R.Anim.Sci.

Louise A. Buckley BSc (Hons), BA (Hons), PG Cert (TLHEP), PGDip, PhD, FHEA, RVN

Department of Animal Production, Welfare and Veterinary Sciences, Harper

Adams University, Newport, Shropshire TF10 8NB, UK; The Jeanne Marchig

International Centre for Animal Welfare Education, The Royal (Dick) School of

Veterinary Studies, The University of Edinburgh, Easter Bush Campus, Midlothian

EH25 9RG, UK

\begin{abstract}
This article aims to give student veterinary nurses undertaking an honours research project (HRP) some ideas for how they might identify a suitable topic to research. It started from the premise that the final year honours degree dissertation project is an exciting opportunity for veterinary nursing students to contribute to the history of veterinary nursing through innovation in the discipline and thus should be embraced. A range of tips for topic identification are outlined, including finding a topic area, searching tips to get you started and prospects for building on previous student ideas and projects.
\end{abstract}

\section{Introduction}

Possibly one of the most challenging parts of the veterinary nursing honours degree course is the opportunity to undertake a dissertation. The dissertation is an extended piece of work (around 10,000 words and 300-400 hours of study) that can be worth $30-40$ credits in the final undergraduate year. Given that the whole year is usually worth 120 credits, the student veterinary nurse can really appreciate how important this dissertation is to the successful completion of their BSc(Hons) in Veterinary Nursing (or similar). For some students the dissertation will be an extended literature review of their chosen topic. However, for most it will include both a review of the literature that identifies a research gap, followed by a primary research study in which the student designs and carries out a study to investigate this gap. This article focuses on getting started with the undergraduate dissertation project and will hopefully provide reassurance that the dissertation is nothing to be worried about but rather, is an opportunity for originality and creativity.

\section{Exciting times....}

Undertaking a dissertation should be challenging but it should also be exciting. The RCVS Day One Competencies (RCVS, 2014) requires registered veterinary nurses to be able to practice evidence-based veterinary nursing from day one of being qualified. When carried out with rigour and commitment and then shared with the wider community (see: Buckley and Mansbridge, 2018), your final year dissertation project has a very real chance of being part of this evidence base. Take a moment to reflect on this. You <insert name your

name in capitals, and then bold and underline this > could undertake work that has the potential to CHANGE and /or INFORM the way that veterinary nurses' nurse - and you haven't even qualified yet! Embrace this opportunity to play a part in veterinary nursing history. 


\section{Help! I don't know what to research...}

If a pound was given for every time a student (not just veterinary nursing students) said this, both authors would be very rich indeed. Sometimes students have a very clear idea as to what they want to do and how. That is great, but it is also relatively rare, so do not worry if this doesn't sound like you. Towards the start, most students sit between having an idea of what they might like to research and having not much idea at all (often combined with dread at the thought of doing the dissertation). You will succeed, but behind every good dissertation is a good idea and that requires some inspiration, effort and consideration to choose the topic that is right for you.

\section{The following tips may help you:}

- Make a list of the broad areas of veterinary nursing that you find particularly interesting or rewarding. Researching a topic or area of nursing that will enthuse you is essential to successful completion. You will work largely as an independent researcher. Although you can, and should, have regular progress and guidance meetings with your supervisor, ultimately this is a project that you will project manage. It is much easier to do this if you love the topic right from the start. Believe us, there will still be times throughout the year when you will still dislike your topic or wonder why you bothered (e.g. if you get a low response rate on a questionnaire), so it is a definite plus to start off on a positive note.

- Once you have your list, think about smaller areas within this that you might be interested in researching and write those down. For example, you might have initially written down: "nurse clinics". Now think about what type of nurse clinics interest you and which interest you enough to sustain your enthusiasm in researching an aspect of them for the next approximately eight months. You might consider ranking them according to your interest in them.

- Think about your placements and the experiences that you had. This could be a very useful source of ideas. Reflect on your experiences. Was there anything that made you question what you did and why? What particularly interested you? Could this be turned into a research project?

- Ask your university and college tutors for advice and guidance right at the outset. They may have research projects already devised that you can be a part of. It will help if you already have an idea of what areas of veterinary nursing interests you. However, do not be tempted to accept a topic/area of research just because the supervisor is interested in this area. If the topic doesn't interest you, while it is possible you might be lucky and develop an interest, it could simply become a stone around your neck for the final academic year as you struggle with the motivation to devise a study, collect the data and then write up a substantial piece of work.

- Visit your university library and have a look at dissertations that students have carried out in previous years. Have a read of ones that interest you. Could you adapt this into a new situation, with a different population of animals, clients, etc.? Was there a problem with the methodology that means that the findings are questionable? Could you redesign the study to remove that problem? Many excellent research projects are developing projects that have been carried out in previous years and extending on these findings. See Figure 1 for an example of how one student dissertation project inspired others at Harper Adams University.

FIGURE 1 GOES CLOSE TO HERE 
- Checking out dissertations can also help you to identify a supervisor who might be right for your dissertation. If the same supervisor's name crops up repeatedly as a supervisor for a particular theme that you are interested in this is a very good clue that they would be worth chatting to about research in this area. They will probably have lots of ideas for research building on previous projects.

- If practical, you visit the library of other colleges and universities that offer an honours degree in veterinary nursing and look at their graduates' undergraduate dissertations. There is no charge to do this, but you probably won't be able to photocopy or take the dissertations away with you. Call ahead and make sure they do put a copy of the dissertations in the library though! Sometimes this information is available through inter-library loans and/or online repositories. Your librarian may be able to help you here, so it is worth having a chat with them.

- Visit PubMed (www.ncbi.nlm.nih.gov/pubmed/) and see what our human focused counterparts are researching (and how they are doing it). In a simple search for this article, the key word search "(nurse OR nursing) AND (research OR researching)" yielded 245879 hits. A scan down this list of hits provides a rich (if unfocused) source of potential topics that could be adapted meaningfully for the veterinary nursing dissertation. To provide a more focussed search to get ideas, include key words for the area of nursing that you are interested in. See table one for examples of this.

\section{TABLE ONE GOES CLOSE TO HERE}

- If you are interested in other disciplines not generally researched by human nurses then it would be worthwhile adapting the PubMed search but using a database more suited to the type of research that you are interested in. CAB Abstracts (or its smaller, sub-section, Vet Med Resource), with the most superior coverage of veterinary - related journals (Grindley et al., 2016) and Web of Science are two databases here that will be of use to you. If you are not sure if your university or college has access to these, ask the librarian for help here. They are an under used resource and have much to offer the student embarking on their dissertation. Try playing with the search terms used. Somewhere, out there is the research study of your dreams just waiting to be adapted or built upon to develop new research questions.

- Check out the clinical abstracts for BVNA and BSAVA congresses to see what veterinary nursing research has been published there. If you are visiting these congresses take time to go and listen to some of the clinical abstract presentations and peruse the posters. Could any of these studies act as inspiration for a future dissertation topic you might like to undertake?

- Spend time on Facebook. Yes, that is right. Spending time on Facebook could help you find a current topic suitable for research. Vet Nurse Chatter is a Facebook group set up by veterinary nurses for veterinary nurses and, at the time of writing, had 13, 257 members! If you are not a member yet, you should consider it. The wide range of discussions that are had by its members reflect the interests, concerns, worries, clinical and non-clinical interests of its membership. These are therefore topics of interest to veterinary nurses, and thus of use to yourself as you look for a topic to interest you that will also interest the wider nursing community.

- Whatever area of research you choose to research, make sure that there is sufficient peer-reviewed research in the general area to allow you to write a sustained piece of academic writing (the literature 
review - even if you are undertaking an piece of original primary research, you are still likely to need to write circa 5000 words reviewing the literature as well). There may be very limited information in your specific area (e.g. obesity clinics from a nursing perspective) making this a research gap (great now research an aspect of it!) but is there a wider body of literature that can be used to produce a literature review in this area? It is worth speaking to your tutors here who will have between them many years of experience guiding students towards suitable themes and literature areas.

Hopefully this set of tips will help you, the student just starting to consider undertaking their final year dissertation topic, think of ways to identify topics that might be of interest to you as an area of research. In the next of these articles, the authors will consider how to turn one of these topics of interest into an area of research suitable for an undergraduate, time-constrained, dissertation.

References:

Buckley, L. A. and Mansbridge, S. C. (2018) Sixteen tips for getting started in practice based research. Veterinary Nursing Journal 33(1): $30-32$

Grindley, D. J. C., Brennan, M. L. and Dean, R. (2016) Searching the veterinary literature: a comparison of the coverage of veterinary journals by nine bibliographic databases. Journal of Veterinary Medical Education 39(4): $404-412$

Royal College of Veterinary Surgeons (2014, RCVS VN day one competencies [Online] RCVS, available from: www.rcvs.org.uk (accessed: 10/03/2018)

Published undergraduate research projects referred to in figure one:

Buckley, L. and Whalley, C. (2012) Does giving dogs their preferred substrate affect willingness to urinate? WSAVA/BSAVA Congress, Birmingham, UK

Straker, J. and Buckley, L. A. (2013) The use of fake grass as an elimination substrate: do hospitalised off leash dogs prefer this to concrete? BSAVA Congress, Birmingham, UK - with the permission of BSAVA, this research was also presented at BVNA Congress 2013, Telford, UK

Teer, S. and Buckley, L. A. (2011) To wee or not to wee? Hospitalised female canines (Canis familiaris) preferred Astroturf to concrete in a two way simultaneous presentation choice test. 45 th Congress of the International Society for Applied Ethology, Indianapolis, USA

Table one: Using human nurse research to inspire the veterinary nursing dissertation: finding a broad range using the PubMed database 


\begin{tabular}{|l|l|l|}
\hline Area of potential interest & PubMed search terms (example of) & Number of hits \\
\hline Compassion fatigue & (nurse OR nursing) AND ("compassion fatigue") & 314 \\
\hline $\begin{array}{l}\text { Intravenous catheter } \\
\text { management }\end{array}$ & $\begin{array}{l}\text { ("intravenous catheter" OR "peripheral catheter") AND } \\
\text { (management OR care OR nurse OR infection OR } \\
\text { complication OR flush OR flushing) }\end{array}$ & 767 \\
\hline Infection control & (nurse OR nursing) AND ("infection control") & 7006 \\
\hline
\end{tabular}

${ }^{ \pm}$Please note: 1 . This is an example of search. It is deliberately left very broad at this stage to allow the student veterinary nurse to identify a wide range of possible research ideas within a given theme. This could be made narrower in focus as the student develops a better idea of the specific area they wish to investigate (e.g. Infection control $>$ hand hygiene $>$ hand hygiene in the hospital environment $>$ hand hygiene in the intensive care unit when placing urinary catheters, etc).

Figure 1: An example of how one final year veterinary nursing honours research project inspired new research questions that led to three more veterinary nursing research projects (two dissertations, one externally funded scholarship) at Harper Adams University. 


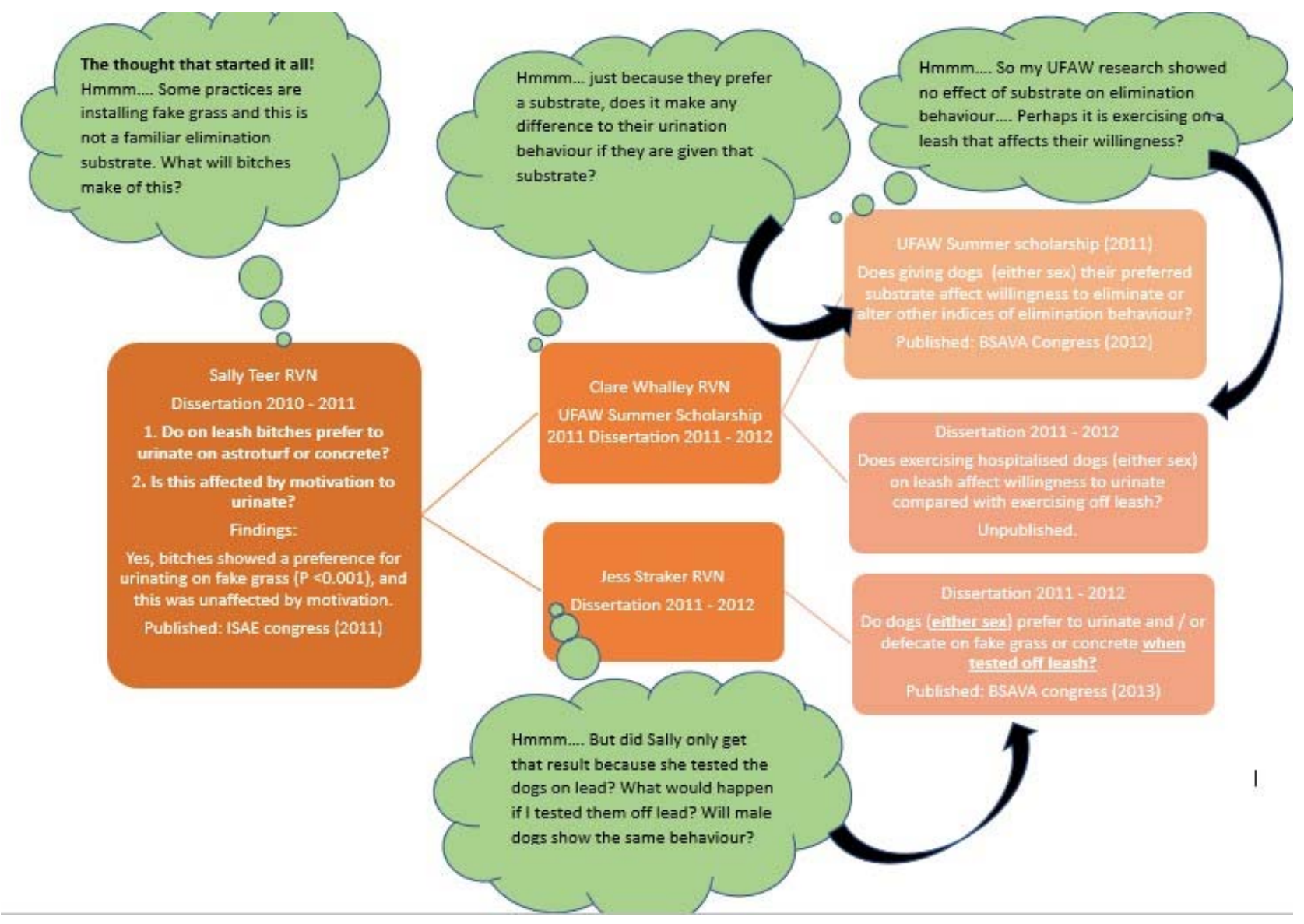

